\title{
Erratum to: Regulatory effect of stems on sucrose-induced chlorophyll degradation and anthocyanin synthesis in Egeria densa leaves
}

Tadayuki Momose $\cdot$ Yoshihiro Ozeki

Published online: 17 August 2013

(C) The Botanical Society of Japan and Springer Japan 2013

\section{Erratum to: J Plant Res}

DOI 10.1007/s10265-013-0581-3

In the section 'Results' of the original publication, the value $0.4 \mathrm{M}$ has been inadvertently published incorrectly as 0 . M. This error was caused during the production process. The correct sentence should read as given below:

In the $0.4 \mathrm{M}$ sucrose culture, the onset of visible damage was more rapid and the detached leaves had turned brown after three days of incubation.

The online version of the original article can be found under doi:10.1007/s10265-013-0581-3.

T. Momose · Y. Ozeki $(\bowtie)$

Department of Biotechnology and Life Science,

Faculty of Engineering, Tokyo University of Agriculture

and Technology, 2-24-16 Naka-cho, Koganei,

Tokyo 184-8588, Japan

e-mail: ozeky@cc.tuat.ac.jp 